\title{
Os professores de educação física e as práticas pedagógicas dos temas transversais com os alunos do ensino básico de escolas públicas
}

\section{The physical education teachers and their relationships to transversal themeswhit primary school students of public school}

\section{Profesores de educación física y sus relaciones con temas transversales con estudiantes en escuelas públicas}

\author{
(iD) Philipe Guedes Matos \\ Universidade do Sul de Santa Catarina, Tubarão, Santa Catarina, Brasil \\ e-mail: phi.guedes@gmail.com \\ iD? Carina Cechinel da Silva \\ Universidade do Sul de Santa Catarina, Tubarão, Santa Catarina, Brasil \\ e-mail: cechinelca@outlook.com
}

\begin{abstract}
Resumo: Muito se discute sobre a importância de abordar determinados assuntos com as crianças e os adolescentes, dentre eles estão a sexualidade, as drogas, a violência doméstica e o preconceito. Os objetivos desta pesquisa foram: verificar como os professores de Educação Física tratam assuntos transversais com seus alunos e investigar a prática pedagógica desses professores em relação a esses temas. A amostra foi composta por 10 professores de Educação Física. O instrumento da pesquisa foi um questionário com perguntas abertas descritivas e fechadas objetivas. Com esta pesquisa foi observado que os professores tratam pouco desses assuntos em aula com seus alunos, pois têm dificuldades em abordar muitos desses temas, porém, quando isso é conversado, a
\end{abstract}


metodologia que a maioria prefere utilizar se dá por meio de rodas de conversas, debates e/ou trabalhos.

Palavras-chave: Educação Física. Professores. Sexualidade.

Abstract: Much is discussed about the importance of addressing certain issues with children and adolescents, among them are sexuality, drugs, domestic violence and prejudice. The objectives of this research were: To verify how Physical Education teachers treat transversal subjects with their students and to investigate the Physical Education teacher's pedagogical practice in relation to transversal themes. The sample consisted of 10 Physical Education teachers. The research instrument was a questionnaire with open descriptive and objective closed questions. With this research it was observed that teachers deal little of these subjects in the classroom with their students, because many of these themes they have difficulties in approaching, but when talked about, the methodology that most use is through conversation circles, debates and works.

Keywords: Physical education. Teachers. Sexuality.

Resumen: Se discute mucho sobre la importancia de abordar ciertos problemas con niños y adolescentes, entre ellos la sexualidad, las drogas, la violencia doméstica y los prejuicios. Los objetivos de esta investigación fueron: Verificar cómo los maestros de Educación Física tratan temas transversales con sus alumnos e investigar la práctica pedagógica del maestro de Educación Física en relación con temas transversales. La muestra consistió en 10 maestros de educación física. El instrumento de investigación fue un cuestionario con preguntas abiertas descriptivas y objetivas cerradas. Con esta investigación se observó que los maestros tratan poco de estas materias en el aula con sus alumnos, porque muchos de estos temas tienen dificultades para abordar, pero cuando se habla, la metodología que más utilizan es a través de círculos de conversación, debates y trabajos.

Palabras clave: Educación Física. Maestros. Sexualidad.

Submetido em: 31-07-2020

Aceito em: 27-04-2021 
Os professores de educação física e as práticas pedagógicas dos temas transversais... Philipe Guedes Matos • Carina Cechinel da Silva

\section{Introdução}

Muito se discute sobre a importância de abordar determinados assuntos com as crianças e os adolescentes, dentre eles estão a sexualidade, as drogas, a violência doméstica (VD) e o preconceito.

Desde 1997, os chamados temas transversais: ética, saúde, meio ambiente, orientação sexual e pluralidade cultural são obrigatórios pelo MEC nos Parâmetros Curriculares Nacionais (PCN), mas cada instituição de ensino pode optar pela forma de abordá-los em sala de aula. As disciplinas tradicionais não dão conta do conjunto de questões posto pela realidade vivida pelos alunos. Segundo o documento, a escola precisa se preocupar em tratar tanto de valores quanto de conhecimentos que "permitam desenvolver as capacidades necessárias para a participação social efetiva" (BRASIL, 1997a, p. 23).

Embora os PCN apontem a importância das disciplinas tradicionais para que os alunos dominem o saber socialmente, "há questões urgentes que devem necessariamente ser tratadas, como a violência, a saúde, o uso de recursos naturais, os preconceitos, que não têm sido diretamente contemplados por essas áreas" (BRASIL, 1997a, p. 23). A Base Nacional Comum Curricular (BNCC) menciona a incorporação ao currículo escolar de temas contemporâneos que afetam a vida humana e que preferencialmente devem ser mediados de forma transversal e integradora, destacando os temas: direitos da criança e do adolescente; educação para o trânsito; educação ambiental; educação alimentar e nutricional; processo de envelhecimento, respeito e valorização do idoso; educação em direitos humanos; educação das relações étnico-raciais e ensino de história e cultura afro-brasileira, africana e indígena; saúde, vida familiar e social; educação para o consumo, educação financeira e fiscal; trabalho, ciência e tecnologia e diversidade cultural (BRASIL, 2017).

Mas, como integrar esses temas às aulas de Educação Física? Quais as dificuldades dos professores em tratar tais assuntos com 
Os professores de educação física e as práticas pedagógicas dos temas transversais... Philipe Guedes Matos • Carina Cechinel da Silva

seus alunos? Será que nas trajetórias acadêmicas desses professores foi trabalhado em algum momento sobre como abordar os temas transversais?

Essa discussão apresenta um aspecto que pode ser emblemático, pois indica que os professores de Educação Física se inserem na escola sem saber as intencionalidades da Educação Física Escolar na contemporaneidade, tomam como ponto de partida a legislação e a produção teórica da área (BAGNARA; FENSTERSEIFER, 2019, p. 5).

Percebemos a necessidade de tratar a Educação Física escolar como um processo de formação educativa, tendo espaço na formação inicial para momentos de debate sobre os aspectos políticos da escola e suas necessidades, sem esquecer o objeto de conhecimento da Educação Física escolar, a cultura corporal (BAGNARA; FENSTERSEIFER, 2019). Dessa forma, há indícios de que os professores de Educação Física muitas vezes não têm a clareza conceitual sobre a intencionalidade para a qual está sendo inserido na escola, pois, muitas vezes em seu período de graduação, foram trabalhadas matérias voltadas exclusivamente para os aspectos de desenvolvimento motor, aspectos físicos, do exercício, dos esportes etc.

Para uma melhor delimitação do estudo, optou-se em investigar os temas contemporâneos transversais: sexualidade, drogas, violência doméstica, qualidade de vida e preconceito.

Dessa forma, o presente trabalho teve por objetivos: verificar como os professores de Educação Física tratam assuntos transversais com seus alunos e investigar a sua prática pedagógica em relação a esses temas, o que contribuiu diretamente para estudos em como abordar os temas transversais no âmbito escolar. 
Os professores de educação física e as práticas pedagógicas dos temas transversais... Philipe Guedes Matos • Carina Cechinel da Silva

\section{Método}

Esta pesquisa se caracteriza como descritiva, através de um levantamento de dados, com abordagem qualitativa e corte transversal. A população da pesquisa foi de professores de Educação Física de Escolas Estaduais do Município de Tubarão. A amostra foi composta por conveniência não probabilística, contendo 10 professores de Educação Física de ambos os sexos, maiores de 18 anos. $\mathrm{O}$ instrumento da pesquisa foi um questionário com perguntas abertas descritivas e fechadas objetivas, com o objetivo de verificar as práticas pedagógicas referentes aos temas transversais.

A pesquisa foi aprovada pelo Comitê de Ética e Pesquisa pelo número 3.499.857 (CAAE 04267018.7.0000.5369) e, no primeiro momento, a Coordenadoria Regional de Educação de Santa Catarina autorizou o acesso às escolas estaduais do município de Tubarão e foram aplicados os questionários aos professores. Assim, foi explicado à direção da Escola de Educação Básica Henrique Fontes sobre o presente estudo e então foram solicitados os horários dos professores de Educação Física do Ensino Fundamental I, II e Ensino Médio, para assim facilitar e organizar as idas dos pesquisadores às escolas. Dessa forma, foram entregues os termos de consentimento livre e esclarecido juntamente ao questionário. A coleta de dados foi iniciada em setembro de 2019.

Antes de aplicar o questionário aos professores, foi explicados a eles os objetivos da pesquisa e o tempo estimado para responderem o questionário, que é de aproximadamente 15 minutos. Finalizadas as coletas, foram tabulados os dados e finalizada a pesquisa.

As variáveis desta pesquisa foram: sexo, idade, local de formação, ano de formação, as respostas relacionadas aos temas transversais de característica fechada objetiva. Para analisar essas variáveis foi utilizada estatística descritiva com medidas de tendência central e dispersão das variáveis quantitativas e frequências absolutas e relativas das variáveis qualitativas. As respostas aos 
Os professores de educação física e as práticas pedagógicas dos temas transversais... Philipe Guedes Matos • Carina Cechinel da Silva

questionários de característica aberta descritiva foram analisadas de forma qualitativa.

\section{Resultados e discussão}

A Tabela 1 mostra as variáveis usadas nesta pesquisa, sendo que, na amostra, metade foi do sexo feminino e a outra metade do sexo masculino. Foi observado também que seis desses professores se formaram na UNISUL (Universidade do Sul de Santa Catarina), enquanto dois na UNESC (Universidade do Extremo Sul Catarinense) e os outros dois na UNIASSELVI (Centro Universitário Leonardo da Vinci). Vale ressaltar que na UNIASSELVI a graduação é realizada no formato a distância.

Em relação às respostas deste questionário, quatro professores responderam se baseando em apenas um ensino (Ensino Fundamental I, Ensino Fundamental II ou Ensino Médio) enquanto seis professores se basearam em mais de um ensino, isso se deve à atuação desses professores nos níveis de ensino que estavam e que já lecionaram. Foi analisada a formação desses professores, sendo que metade atua há menos de 10 anos e a outra metade há mais de 10 anos. 
Os professores de educação física e as práticas pedagógicas dos temas transversais... Philipe Guedes Matos • Carina Cechinel da Silva

Tabela 1 - Resultados descritivos da amostra

\begin{tabular}{|c|c|c|c|c|}
\hline & Variável & $\mathrm{N}$ & & \\
\hline \multirow[t]{3}{*}{ Sexo } & Feminino & 5 & & \\
\hline & Masculino & 5 & & \\
\hline & Total & 10 & & \\
\hline \multirow{4}{*}{$\begin{array}{l}\text { Local de } \\
\text { formação }\end{array}$} & UNISUL & 6 & & \\
\hline & UNESC & 2 & & \\
\hline & UNIASSELVI & 2 & & \\
\hline & Total & 10 & & \\
\hline \multirow[t]{3}{*}{ Ensino } & Apenas um ensino & 4 & & \\
\hline & Mais de um ensino & 6 & & \\
\hline & Total & 10 & & \\
\hline \multirow[t]{5}{*}{ Formação } & Menos de 10 anos & 5 & & \\
\hline & Mais de 10 anos & 5 & & \\
\hline & Total & 10 & & \\
\hline & Variável & Valor Mínimo & Valor Máximo & ? $\pm \mathrm{DP}$ \\
\hline & Idade & 23 & 53 & $33,60 \pm 10,03$ \\
\hline
\end{tabular}

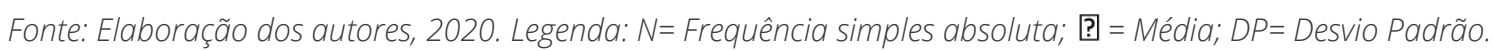

A seguir apresentamos o Gráfico 1 sobre a atuação do professor de Educação Física nas temáticas relacionadas aos temas transversais.

Gráfico 1 - Você aborda os temas transversais com seus alunos?

\section{Em suas aulas você costuma conversar com os}

seus alunos sobre os temas transversais sexualidade, drogas (álcool e tabagismo), violência doméstica e qualidade de vida?

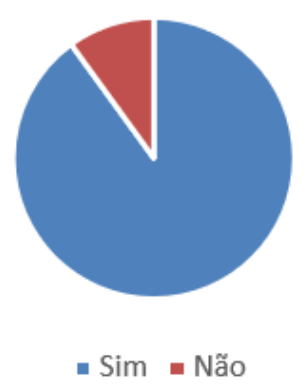


Os professores de educação física e as práticas pedagógicas dos temas transversais... Philipe Guedes Matos • Carina Cechinel da Silva

A primeira questão do questionário era se os professores abordavam os temas transversais com seus alunos e, com o Gráfico 1, podemos observar que a maioria respondeu que sim, sendo que nove dos professores abordavam com seus alunos sobre os temas transversais, enquanto apenas um respondeu que não. O Gráfico 2 elucida o grau de dificuldade de trabalhar os temas transversais pelos professores.

\section{Gráfico 2 - Grau de dificuldade em abordar tais temas transversais com seus alunos.}

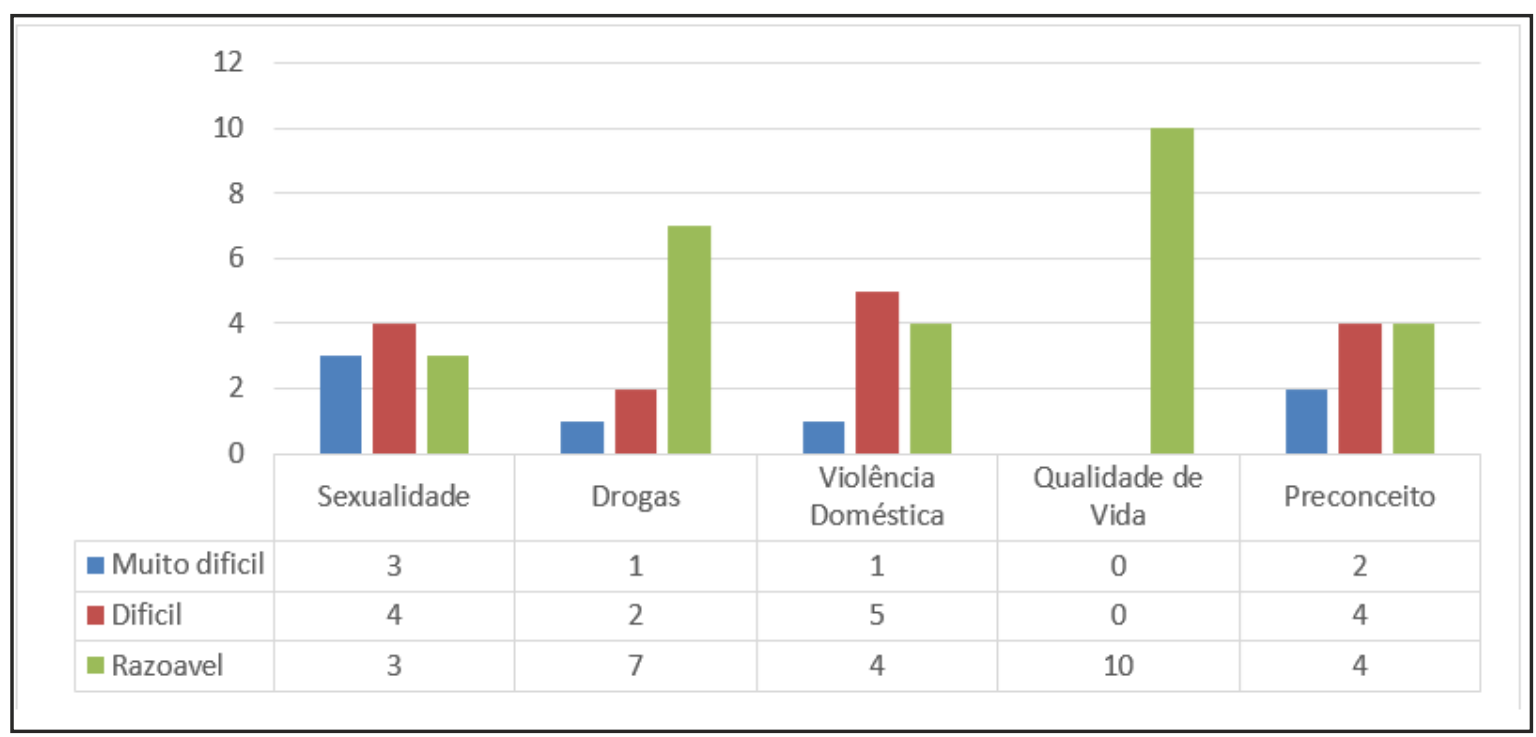

Fonte: Elaboração dos autores, 2020

A investigação do estudo foi baseada em questionamentos sobre a relação da abordagem dos temas transversais com os alunos, buscando analisar como essa temática tem sido trabalhada pelos professores de Educação Física frente às suas atividades pedagógicas. Para melhor organizarmos a discussão, traremos trechos das respostas dos professores, sendo que a íntegra pode ser encontrada nos apêndices do artigo. Para preservar a identidade dos professores eles foram representados pelas letras do alfabeto, do A até o J e por siglas $P=$ Professor, como exemplo a sigla PA representa parte da resposta do professor $A$. 
Os professores de educação física e as práticas pedagógicas dos temas transversais... Philipe Guedes Matos • Carina Cechinel da Silva

Foi questionado aos professores, que abordam os temas transversais com os alunos, de que forma eles atuam com a intenção de perceber quais metodologias eram utilizadas. A seguir, o Quadro 1 com as respostas dos professores sobre como eles atuam com os temas transversais e quais as suas dificuldades.

Quadro 1 - Questão 2a: Se sim, de que forma você aborda tais assuntos em suas aulas? E quais foram as dificuldades encontradas?

\begin{tabular}{|l|l|}
\hline Professor & Resposta \\
\hline & $\begin{array}{l}\text { Abordo de forma de conversa pós e pré-aula, como forma de inter- } \\
\text { ação. Sem dificuldades. }\end{array}$ \\
\hline & $\begin{array}{l}\text { Utilizo situações da aula ou da sociedade para introduzir os assuntos. } \\
\text { A dificuldade é encontrada em temas que não fazem parte do cotidia- } \\
\text { no ou vida do aluno. }\end{array}$ \\
\hline & $\begin{array}{l}\text { Trabalho em forma de jogos, rodas de conversa e trabalhos. As dificul- } \\
\text { dades estão relacionadas ao preconceito dos alunos ou a vergonha de } \\
\text { falar abertamente sobre tais temas. }\end{array}$ \\
\hline & $\begin{array}{l}\text { Seminários e de forma expositiva. Dificuldade em transformar a infor- } \\
\text { mação em conhecimento. }\end{array}$ \\
\hline & $\begin{array}{l}\text { Observo situações adversas e tento da melhor maneira orientar e } \\
\text { tirar dúvidas através de conversas. }\end{array}$ \\
\hline & $\begin{array}{l}\text { Abordo em momentos de conflito, quando os alunos trazem para o } \\
\text { cotidiano das aulas. }\end{array}$ \\
\hline & $\begin{array}{l}\text { Em forma de aulas planejadas e também quando precisa intervir em } \\
\text { situações mais delicadas. }\end{array}$ \\
\hline & Através de trabalhos e roda de conversas. \\
\hline $\begin{array}{l}\text { Através de filmes, trabalhos de pesquisas e debates. Dificuldade com } \\
\text { alunos que não gostam de apresentar ou discutir o assunto trabalha- } \\
\text { do. }\end{array}$ \\
\hline
\end{tabular}

Fonte: Elaboração dos autores, 2020.

Percebemos que existe uma inconsistência em relação às abordagens utilizadas pelos professores e, nesse sentido, o planejamento se torna essencial. É necessária, na seleção dos conteúdos, a promoção de uma concepção científica de mundo. Além disso os conteúdos precisam ser organizados e sistematizados, possibilitando o conhecimento da natureza e da sociedade, dessa forma o método deve apontar o desenvolvimento da atividade e 
Os professores de educação física e as práticas pedagógicas dos temas transversais... Philipe Guedes Matos • Carina Cechinel da Silva

de um sistema de relações sociais entre os homens (CASTELLANI FILHO et al., 2014).

É preciso ressaltar que esta pesquisa não se preocupou em investigar a eficácia dos métodos adotados para atuar com os temas transversais, e sim, quais foram utilizados pelos professores, no entanto nos cabe uma reflexão sobre a efetividade das abordagens realizadas, principalmente em relação ao planejamento, que não está presente nas respostas da maior parte dos professores.

Nunes et al. (2017) destacam ainda a necessidade de planejar coletivamente e vincular o planejamento ao Projeto PolíticoPedagógico da escola, visando existir coerência entre o que se planeja com a visão da sociedade em que vivemos e do que queremos para nossos alunos. Além disso, quando o professor realiza um planejamento, ele coloca a Educação Física como importante componente curricular.

Observamos que na fala dos professores em relação à sexualidade, a maioria considera o tema difícil, como é possível observar:

Não conseguem se abrir para conversar a respeito, não se sentem à vontade com a turma e nem com o professor [...] (PA). Não procuro abordar esses assuntos, pois não sei como seria a reação dos familiares. Esse assunto fica para mediação [...] (PG). Tema trabalhado com muito cuidado [...] (PJ).

Segundo Brasil (1997b), deve-se problematizar, levantar questionamentos e ampliar o leque de conhecimentos e de opções, para que o aluno, ele próprio, escolha seu caminho. As diferentes temáticas da sexualidade devem ser trabalhadas dentro do limite da ação pedagógica, sem serem invasivas da intimidade e do comportamento de cada aluno.

O professor de Educação Física, assim como os demais professores, deverá, dentro da sua especificidade e especialização, e estando consciente que a sua disciplina faz parte de um todo que é a Educação, fazer da busca teórica a sua maior aliada para 
Os professores de educação física e as práticas pedagógicas dos temas transversais... Philipe Guedes Matos • Carina Cechinel da Silva

a superação dos entraves que ocorrem na sua prática profissional, tornando o seu fazer pedagógico mais eficiente, tendo sempre presente a promoção do crescimento do aluno como um todo, e tendo claro ainda que as questões vivenciadas por este aluno no seu cotidiano não podem ficar alheias aos conteúdos de cada disciplina (BIANCO, 2017).

No estudo de Vieira e Matsukura (2017), que analisaram as práticas de educação sexual em escolas, verificou-se que a maior parte das intervenções foi realizada pelo professor de ciências da escola, partindo dos conteúdos apresentados pelos currículos disciplinares e associados à orientação e prevenção de doença sexualmente transmissível (DST) e gravidez. Quando analisamos as dificuldades dos professores em tratar a temática, podemos ressaltar a falta de conhecimento e a possível interferência dos pais de forma negativa sobre o assunto, como fatores mais significativos (BARBOSA; FOLMER, 2019).

Levando em consideração as dificuldades da temática, Ew et al. (2017) apresentam uma intervenção possível, através de oficinas baseadas em uma metodologia participativa, apontando uma percepção positiva das ações por parte dos alunos. As pesquisas que tratam de Educação Física e sua relação com sexualidade estão mais centradas na temática gênero, enquanto sexualidade tem uma função coadjuvante nessas pesquisas (SABATEL et al., 2016). Para efetivamente protagonizarmos a temática na escola, precisamos trabalhar de forma transversal e comunicando-nos com todos os atores envolvidos no contexto escolar. Vale ressaltar a necessidade de investimentos em formação e formação continuada que usem metodologias que priorizem o aprendizado, centradas nas experiências, saberes e cenários reais da escola (CADILHE, 2017; ZERBINATI; BRUNS, 2017).

Em relação às drogas, a fala dos professores, em sua maioria, considera o tema razoável de conversar com seus alunos, como é possível observar: 
Os professores de educação física e as práticas pedagógicas dos temas transversais... Philipe Guedes Matos • Carina Cechinel da Silva

São abertos a diálogos e reconhecem que faz mal, porém muitos acham normal[...] (PE).

Demonstram interesse, pois sempre tem "exemplos". Conhecem os perigos[...] (PG).

Socializam com mais facilidade, pois conhecem pessoas e casos a relatar[...] $(\mathrm{PH})$.

O uso de drogas se configura como uma problemática atual que vem crescendo a cada dia, o estudo de Beserra et al. (2019) encontrou uma prevalência excessiva para uso de álcool, tabaco e drogas ilícitas entre adolescentes. Horta et al. (2018) apresentam um índice de 9\% no uso de drogas ilícitas entre adolescentes, sendo mais prevalente o uso pelas meninas, sendo esse uso relacionado ao consumo de álcool, tabaco e à atividade sexual. O que se percebe muitas vezes é o despreparo das pessoas para enfrentar essa situação. Uma abordagem pedagógica dessa problemática no contexto escolar é necessária, pois possibilitaria identificar e discutir o problema junto aos alunos e propor práticas preventivas que sejam bem-sucedidas para sua possível divulgação, bem como levantar possíveis sugestões deles dentro da área preventiva (MURER; DE FARIA OLIVEIRA; MENDES, 2009).

De acordo com Soibelaman (2003), muitas pesquisas sobre o uso de drogas revelam que o primeiro contato ocorre, na maioria das vezes, na própria escola, destacando que um dos fatores que vem a influenciar o consumo é a falta de informação sobre o efeito das drogas. Esta constatação traz para a escola a responsabilidade de abordar o assunto em sala de aula, pois todo o público escolar está de alguma forma em contato com essa situação. O estudo de Pereira; Paes e Sanchez (2016), que realizaram um levantamento de quantas escolas de São Paulo, apresentou programas de prevenção ao uso de drogas encontrou um índice 42,3\%. No entanto, as dificuldades em implantar um programa estavam relacionadas à falta de material didático, falta de dinheiro e às demandas concorrentes para ensino de outras disciplinas. 
Os professores de educação física e as práticas pedagógicas dos temas transversais... Philipe Guedes Matos • Carina Cechinel da Silva

O professor de Educação Física pode ser um grande aliado da comunidade escolar para a prevenção ao uso de drogas, em virtude do seu conhecimento sobre os benefícios da atividade física que atuam na autoestima do praticante, possibilitando a diminuição do stress, ansiedade, e que, dessa forma, pode ser utilizado na conscientização dos estudantes (ANDRADE; CASTILHO, 2016).

Em relação à violência doméstica, a fala dos professores, em sua maioria, considera o tema difícil de conversar com seus alunos, como é possível observar:

Sem o que comentar, não entrei ainda no tema[...] (PB).

Tema complicado de abordar[...] (PC).

Pouco comentado e não se abrem pra esse tema[...] (PE).

A VD representa toda ação ou omissão que prejudique o bem-estar, a integridade física, psicológica ou a liberdade e o direito ao pleno desenvolvimento de um membro da família. Pode ser cometida dentro e fora do lar por qualquer um que esteja em relação de poder com a pessoa agredida, incluindo aqueles que exercem a função de pai ou mãe, mesmo sem laços de sangue (DAY et al., 2003).

A escola não é um espaço de intervenção propriamente dito, na medida em que não possui autoridade e recursos adequados para apurar e atuar diretamente em casos de violência doméstica, mas pode e deve ser um espaço de prevenção e proteção de seus alunos, através da identificação e comunicação aos órgãos competentes (VAGOSTELLO et al., 2003)

Em 2016, foram registrados 22,9 mil atendimentos a vítimas de estupro no país, segundo dados apurados pela BBC. Mais de $57 \%$ desses casos eram de vítimas entre 0 e 14 anos, sendo que 6 mil vítimas tinham menos de 9 anos de idade (MORI, 2018). A VD contra crianças e adolescentes também está associada ao baixo desempenho escolar, como apresenta a pesquisa de Pereira (2017). Vale ressaltar que a violência sofrida por essa população 
Os professores de educação física e as práticas pedagógicas dos temas transversais... Philipe Guedes Matos • Carina Cechinel da Silva

com baixo desempenho escolar, representada no estudo, foi a verbal/psicológica.

É preciso que os profissionais de saúde e educação, principalmente, estejam atentos para os sinais e sintomas da violência e do abuso sexual contra crianças e adolescentes, visando à detecção e tratamento adequados. Além disto, o conhecimento da legislação e dos meios de proteção legal torna-se necessário para a assistência às vítimas (MARTINS; JORGE, 2010). Muitas vezes os professores têm conhecimento sobre a temática e conseguem identificar em seus estudantes sinais de violência doméstica, no entanto, não sabem como intervir adequadamente e consideram esse fenômeno como algo que deveria ser mais bem enfrentado pela escola (CASCARDO; GALLO, 2018; COSTA; TEIXEIRA, 2017; ELSEN et al., 2011).

Em relação ao tema qualidade de vida, a fala dos professores, em sua maioria, considera o tema fácil de debater e de conversar, como podemos ver,

Mostram interesse, principalmente o Ensino Médio, pois relaciona o tema com a aparência visual[...] (PC).

Bem tranquilo, eles sabem dos malefícios e benefícios[...] (PD). Esse tema é melhor de se trabalhar[...] (PJ).

Entendemos qualidade de vida como a soma de fatores socioambientais e fatores individuais que resultam na percepção de qualidade de vida e bem-estar de cada indivíduo (NAHAS, 2006). No entanto, para ampliar as possibilidades de discussão deste artigo, optou-se pelo termo saúde, além da qualidade de vida. Fica evidente que não podemos reduzir o tema saúde apenas a esse aspecto, pois, segundo a Organização Mundial da Saúde (OMS), a saúde não pode ser entendida apenas como ausência de doenças, mas como um estado de completo bem-estar físico, mental e social (ORGANIZATION, 1947). 
Os professores de educação física e as práticas pedagógicas dos temas transversais... Philipe Guedes Matos • Carina Cechinel da Silva

É importante abordar o ensino da temática saúde nas aulas de Educação Física escolar no intuito de promover a conscientização e a formação de hábitos saudáveis na vida dos alunos (ZANCHA et al., 2013).

Dessa forma, os professores de Educação Física devem direcionar a sua prática para alertar e conscientizar seus alunos em relação à importância de praticar exercícios físicos e passar o conhecimento sobre ter hábitos saudáveis, como alimentação balanceada, ingestão de água etc, quando se tratar dessa temática, é preciso ter cuidado para não reduzir as aulas de Educação Física a um caráter biologicista exclusivamente.

Ou seja, os professores de Educação Física devem incorporar uma nova postura frente à estrutura educacional, procurando proporcionar em suas aulas não mais uma visão exclusiva à prática de atividades esportivas e recreativas, mas, também, para alcançarem metas voltadas à educação para a saúde. Mediante a seleção, organização e desenvolvimento de experiências que possam propiciar aos alunos não apenas situações que os tornem crianças e adolescentes ativos fisicamente, mas, sobretudo, que os conduzam a optarem por um estilo de vida saudável ao longo de toda a vida (NAHAS, 2006).

Colaborando com isso, afirma-se que o professor de Educação Física deve agir como mediador e facilitador de conhecimentos, podendo aplicar suas aulas de maneira atraente e criativa, juntamente a outros conteúdos e atividades, mostrando os benefícios dessas atividades para a saúde (SANTOS; DUQUE, 2010).

O PCN da saúde nos traz que é preciso entender essa temática de forma coletiva, através de um determinante social (BRASIL, 1997c). Se verificarmos as respostas dos professores, apesar de estarem relacionadas à qualidade de vida, ainda são genéricas sobre como exatamente elas são executadas, se são feitas de forma coerente, levando em consideração o entendimento de saúde do $\mathrm{PCN}$. Este mesmo documento ainda reforça que, com a mediação dos professores, os alunos 
Os professores de educação física e as práticas pedagógicas dos temas transversais... Philipe Guedes Matos • Carina Cechinel da Silva

[...] possam estruturar e fortalecer comportamentos e hábitos saudáveis, tornando-se sujeitos capazes de influenciar mudanças que tenham repercussão em sua vida pessoal e na qualidade de vida da coletividade. Para isso, é necessária a adoção de abordagens metodológicas que permitam ao aluno identificar problemas, levantar hipóteses, reunir dados, refletir sobre situações, descobrir e desenvolver soluções comprometidas com a promoção e a proteção da saúde pessoal e coletiva, e, principalmente, aplicar os conhecimentos adquiridos (BRASIL, 1997c).

Em relação ao tema preconceito, a fala dos professores, em sua maioria, encontra dificuldades em abordar, como podemos ver:

A maioria se nega a aceitar que pratica, já está alocado na sociedade, por isso, tema difícil de trabalhar[...] (PC).

Existe bastante dificuldade, em relação a raça, cor, sexualidade mas estão ficando mais conscientes[...] (PF).

Muito difícil, muitos adolescentes não têm respeito ao próxi$\mathrm{mo}[\ldots]$ (PJ).

Os preconceitos são construções sociais, isto é, carregam uma história, e são forjados tanto de forma individual quanto coletiva, no cotidiano. Entende-se como fundamental que a escola proporcione espaços que ampliem a discussão sobre seus diferentes tipos, origens e consequências (CORDEIRO; BUENDGENS, 2012).

Nas escolas, os adolescentes e jovens interagem com outros adolescentes e jovens que são diferentes deles ou de seu grupo de referência, em função, entre outros aspectos, da cor, da sexualidade, da nacionalidade, do corpo, da classe socioeconômica. No espaço escolar essa interação com o diferente, quando não é problematizada, se dá por meio de relações interpessoais pautadas por conflitos, confrontos e violência. É importante que se analise as práticas, valores e informações que se veiculam no âmbito escolar, buscando o desvelamento e não o acobertamento das práti- 
Os professores de educação física e as práticas pedagógicas dos temas transversais... Philipe Guedes Matos • Carina Cechinel da Silva

cas de discriminação e de intolerância que podem gerar violências entre os adolescentes e jovens, e seus pares no contexto escolar (SALLES; SILVA, 2008).

Levando em consideração o relato dos professores, observamos que a Violência Doméstica apresentou maiores dificuldades pela percepção dos pesquisadores. Desta forma, resolvemos dar ênfase a este tema.

Os termos Violência Doméstica e Violência Intrafamiliar (VI) são identificados na literatura com significados ora semelhantes, ora distintos. Entre as próprias pesquisadoras, a seguir, que desenvolvem trabalhos no âmbito da violência contra criança e adolescente, cada qual utiliza um dos termos, Violência Doméstica ou Violência Intrafamiliar, para abordar a violência contra esse público. A definição de Azevedo e Guerra (1995, p. 36) é uma das mais utilizadas em estudos acadêmicos sobre essa temática:

\begin{abstract}
Violência doméstica contra crianças e adolescentes é todo ato e/ou omissão praticado(s) por pais, parentes ou responsável em relação à criança e/ou adolescente que - sendo capaz de causar dor ou dano de natureza física, sexual e/ou psicológica à vítima - implica, de um lado, uma transgressão do poder/dever de proteção do adulto e, de outro, uma "coisificação" da infância, isto é, uma negação do direito que crianças e adolescentes têm de ser tratados como sujeitos e pessoas em condição peculiar de desenvolvimento.
\end{abstract}

Observa-se a preferência do uso do termo Violência Doméstica em detrimento de Violência Intrafamiliar. Outro autor opta pelo termo Violência Intrafamiliar ao se referir às crianças e adolescentes como sendo afetadas por esta.

Quando se detecta a presença da violência dentro de um grupo familiar, costuma-se defini-la como uma questão de violência intrafamiliar (VIF). A VIF determina um padrão de relacionamen- 
Os professores de educação física e as práticas pedagógicas dos temas transversais... Philipe Guedes Matos • Carina Cechinel da Silva

to abusivo entre pai, mãe e filho, que leva ao desencontro, à estereotipia e à rigidez no desempenho dos papéis familiares (FERRARI, 2002, p. 81).

Como mencionado anteriormente, a escola não é um espaço de intervenção propriamente dito, na medida em que não possui autoridade e recursos adequados para apurar e atuar diretamente em casos de violência doméstica, mas pode e deve ser um espaço de prevenção e proteção de seus alunos, através da identificação e comunicação aos órgãos competentes (VAGOSTELLO et al., 2003). Estudos realizados pelo mesmo autor mostram que algumas escolas, embora sejam capazes de identificar casos de violência entre seus alunos, ainda apresentam muitas dificuldades para abordar esse assunto que, quando não é negado e ocultado, acaba sendo equivocadamente tratado.

Em Curitiba, no ano 2000, foi implementada a "Rede de Proteção à Criança e ao Adolescente em Situação de Risco para Violência", cujo foco temático era a violência doméstica (CURITIBA, 2008). Essa rede tem como objetivo contribuir, de forma integrada, para a redução da violência contra a criança e ao adolescente em Curitiba, principalmente no que se refere à violência doméstica/intrafamiliar e sexual (Manual da Rede de Proteção).

\section{4 conclusão}

Observa-se que os professores tratam pouco desses assuntos em sala de aula com seus alunos, pois eles têm dificuldades em abordar muitos desses temas. Porém, quando são tratados, a metodologia que a maioria usa se dá por meio de rodas de conversas, debates e/ou trabalhos.

Constatamos que existe uma maior facilidade de abordar os temas relacionados à saúde, como a qualidade de vida, em que os professores parecem estar mais confortáveis. No entanto, quando apresentamos as demais possibilidades de temas transversais, 
Os professores de educação física e as práticas pedagógicas dos temas transversais... Philipe Guedes Matos • Carina Cechinel da Silva

os professores, em sua maioria, se mostraram desconfortáveis. O tema sexualidade, violência doméstica e preconceito merecem destaque, pois os professores, em sua maior parte, apresentam dificuldades, principalmente relacionadas a como os familiares reagiriam aos temas sexualidade e VD, e a negação da existência de ações preconceituosas.

Quando analisamos as abordagens usadas, esse é um ponto de fragilidade apresentado, principalmente levando em consideração as respostas dos professores, a não existência de um planejamento. Muitas das ações são realizadas a partir de observações ou necessidades apresentadas pelos alunos, o que não é necessariamente algo negativo, mas quando analisamos as temáticas transversais e que elas estão presentes constantemente em nossa sociedade contemporânea, torna-se importante que as práticas pedagógicas tenham um planejamento, organizado e sistematizado, e preferencialmente coletivo, valorizando a interdisciplinaridade.

Podemos destacar uma limitação do estudo em relação às práticas pedagógicas realizadas pelos professores, pois a pesquisa se preocupou em investigar de que forma eram realizadas, e não se as mesmas foram as mais adequadas. Outra limitação foi o número de professores e instituição envolvidos na pesquisa. Dessa forma, sugerimos a investigação da efetividade das práticas pedagógicas de professores de Educação Física em relação aos temas transversais e estudos que envolvam um maior número de professores e instituições de ensino.

Com tantas dificuldades relacionadas em mediar os temas transversais, alguns programas vinculados às universidades, como, por exemplo, o PIBID (Programa Institucional de Bolsas de Iniciação à Docência) e Residência Pedagógica, podem ser significativos para auxiliar nessa prática, podendo sugerir ideias novas e de forma colaborativa com professor de sala, debater e repassar conhecimento sobre temas transversais aos alunos, propondo metodologias mais adequadas para a abordagem desses temas. 
Os professores de educação física e as práticas pedagógicas dos temas transversais... Philipe Guedes Matos • Carina Cechinel da Silva

\section{Referências}

ANDRADE, E. M.; CASTILHO, L. A. S. Contribuição do profissional de educação física no combate as drogas na escola: Revisão sistemática da literatura. Horizontes-Revista de Educação, n. 8, 4, p. 200-211, 2016.

AZEVEDO, M. A.; GUERRA, V. d. A. Violência doméstica na infância e na adolescência. São Paulo: Robe, 1995. 126 p.

BAGNARA, I. C.; FENSTERSEIFER, P. E. Relação entre formação inicial e ação docente: o desafio político da educação física escolar no centro do debate. Revista Brasileira de Ciências do Esporte, 41, n. 3, p. 277-283, 2019.

BARBOSA, L. U.; FOLMER, V. Facilidades e dificuldades da educação sexual na escola: Percepções de professores da educação básica. REVASF, n. 19, 9, p. 221-243, 2019.

BESERRA, M. A.; CARLOS, D. M.; LEITÃO, M. N. d. C.; FERRIANI, M. d. G. C. Prevalência de violência na escola e uso de álcool e outras drogas entre adolescentes. Rev. Latino-Am. Enfermagem, 27, 2019.

BIANCO, A. P. Tema transversal orientação sexual, prática pedagógica do professor de educação física: trajetórias e desafios. 2017. Dissertação de mestrado (Mestre) - Faculdade de Ciências e Letras, Araraquara, Universidade Estadual Paulista.

BRASIL, M. d. E. Parâmetros Curriculares Nacionais:

Apresentação dos temas transversais, ética. FUNDAMENTAL, S. e. E. Brasília: MEC 1997a.

BRASIL, M. d. E. Parâmetros Curriculares Nacionais: pluralidade cultural, orientação sexual. FUNDAMENTAL, S. d. E. Brasília: MEC/ SEF: 164 p. 1997b.

BRASIL, M. d. E. Parâmetros Curriculares Nacionais: Saúde. Fundamental, S. d. E. Brasília: MEC/SEF 1997c. 
Os professores de educação física e as práticas pedagógicas dos temas transversais... Philipe Guedes Matos • Carina Cechinel da Silva

BRASIL, M. d. E. Base Nacional Comum Curricular. Básica, S. d. E. Brasília, DF: MEC 2017.

CADILHE, A. J. "Tenho dificuldades em lidar com essa situação": Narrativas, gênero e sexualidade na formação continuada de professores/as. Revista Humanidades e Inovação, n. 6, 4, 2017. CASCARDO, G. M.; GALLO, A. E. Mapping of the Teachers knowledge on family violence. Revista Psicologia da Educação, 1, n. 46, 2018.

CASTELLANI FILHO, L.; LÚCIA, S. C.; TAFFAREL, C. N. Z.; VARJAL, E. et al. Metodologia do ensino de educação física. Cortez Editora, 2014. 8524920823.

CORDEIRO, A. F. M.; BUENDGENS, J. F. Preconceitos na escola: sentidos e significados atribuídos pelos adolescentes no ensino médio. Psicologia Escolar e Educacional, 16, n. 1, p. 45-54, 2012. COSTA, A. d. L.; TEIXEIRA, K. M. D. O comportamento dos alunos na escola e sua relação com a violência doméstica na percepção dos educadores. Oikos: Revista Brasileira de Economia Doméstica, n. 1, 28, p. 22-42, 2017.

CURITIBA, P. M. Protocolo da rede de proteção à criança e ao adolescente em situação de risco para a violência. Social, F. d. A. Curitiba: Secretaria Municipal de Saúde, 2008.

DAY, V. P.; TELLES, L. E. d. B.; ZORATTO, P. H.; AZAMBUJA, M. R. F. d. et al. Violência doméstica e suas diferentes manifestações.

Revista de psiquiatria do Rio Grande do Sul, 25, p. 9-21, 2003.

ELSEN, I.; PRÓSPERO, E. N. S.; FLORIANO, C. J.; SANCHES, E. N. et al. Escola: Um espaço de revelação da violência doméstica contra crianças e adolescentes. Psicol. Argum., n. 66, 29, p. 303-314, 2011.

EW, R. D. A. S.; CONZ, J.; FARIAS, A. D. G. d. O.; SOMBRIO, P. B. M. et al. Diálogos sobre sexualidade na escola: uma intervenção possível. Revista Psicologia em Pesquisa, 11, n. 2, 2017.

FERRARI, D. C. A. Definição de abuso na infância e na adolescência. In: FERRARI, D. C. A. e VECINA, T. C. C. (Ed.). O fim do silêncio 
Os professores de educação física e as práticas pedagógicas dos temas transversais... Philipe Guedes Matos • Carina Cechinel da Silva

na violência familiar: teoria e prática. São Paulo: Ágora, 2002. v. 81.

HORTA, R. L.; MOLA, C. L.; HORTA, B. L.; MATTOS, C. N. B. et al. Prevalence and factors associated with illicit drug use throughout life: National School Health Survey 2015. Rev. Bras. Epidemiol., 21, n. suppl 1, p. e180007, Nov 292018.

MARTINS, C. B. d. G.; JORGE, M. H. P. d. M. Abuso sexual na infância e adolescência: perfil das vítimas e agressores em município do sul do Brasil. Texto \& Contexto - Enfermagem, 19, p. 246255, 2010.

MORI, L. Levantamento revela caos no controle de denúncias de violência sexual contra crianças. BBC BRASIL. São Paulo. 2018.

MURER, E.; DE FARIA OLIVEIRA, J. D.; MENDES, R. T. Substâncias psicoativas no ambiente escolar. In: BOCCALETTO, E. M. A. e MENDES, R. T. (Ed.). Alimentação, Atividade Física e Qualidade de Vida dos Escolares no Município de Vinhedo/SP. Campinas: IPES Editorial, 2009. p. 89-99.

NAHAS, M. V. Atividade física, saúde e qualidade de vida: conceitos e sugestões para um estilo de vida ativo. Midiograf, 2006. 8590203824.

NUNES, L. d. O.; FONSECA, D. G. d.; BOSSLE, C. B.; BOSSLE, F. Planejamento de ensino e Educação Física: uma revisão de literatura em periódicos nacionais. Motrivivência, 29, n. 52, p. 280294, 2017.

ORGANIZATION, W. H. The constitution of the world health organization. WHO chronicle, v. 1, p. 29.

PEREIRA, A. P.; PAES, A. T.; SANCHEZ, Z. M. Factors associated with the implementation of programs for drug abuse prevention in schools. Rev. Saúde Pública, 50, p. 44, Aug 42016.

PEREIRA, T. C. A violência doméstica e o desempenho escolar de crianças e adolescentes. 2017. Dissertação (Mestre em 
Os professores de educação física e as práticas pedagógicas dos temas transversais... Philipe Guedes Matos • Carina Cechinel da Silva

Ciências da Saúde) - Programa de Pós-Graduação Stricto Sensu, Universidade Santo Amaro - UNISA, São Paulo.

SABATEL, G. M. G.; ALVES, S. D. S.; FRANCISCO, M. V.; LIMA, M. R. C. d. Gênero e Sexualidade na Educação Física Escolar: Um balanço da produção de artigos científicos no período entre 2004-2014 nas bases do Lilacs e Scielo. Pensar a Prática, 19, n. 1, 2016.

SALLES, L. M.; SILVA, J. Diferenças, preconceitos e violência no âmbito escolar: algumas reflexões. Cadernos de Educação, 30, p. 149-166, 2008.

SANTOS, R.; DUQUE, L. Evasão na aula de educação física: fatores que interferem na participação do aluno. Lectures, Educación Física y Deportes. Revista Digital, Buenos Aires, 15, n. 149, 2010. SOIBELMAN, M. Problemas relacionados ao álcool, tabaco e outras substâncias psicoativas (SPA). In: BASSOLS, A. M. (Ed.). Saúde mental na escola - uma abordagem multidisciplinar. Porto Alegre: Meditação, 2003.

VAGOSTELLO, L.; OLIVEIRA, A. d. S.; SILVA, A. M. d.; DONOFRIO, V. et al. Violência doméstica e escola: um estudo em escolas públicas de São Paulo. Paidéia (Ribeirão Preto), 13, n. 26, p. 191-196, 2003.

VIEIRA, P. M.; MATSUKURA, T. S. Modelos de educação sexual na escola: concepções e práticas de professores do ensino fundamental da rede pública. Revista Brasileira de Educação, 22, n. 69, p. 453-474, 2017.

ZANCHA, D.; MAGALHÃES, G. B. S.; MARTINS, J.; DA SILVA, T. A. et al. Conhecimento dos professores de educação física escolar sobre a abordagem saúde renovada e a temática saúde. Conexões, 11, n. 1, p. 204-217, 2013.

ZERBINATI, J. P.; BRUNS, M. A. d. T. SEXUALIDADE E EDUCAÇÃO: REVISÃO SISTEMÁTICA DA LITERATURA CIENTÍFICA NACIONAL.

Travessias, n. 1, 11, p. 76-92, 2017. 
Os professores de educação física e as práticas pedagógicas dos temas transversais... Philipe Guedes Matos • Carina Cechinel da Silva

\section{Apêndice A - quadro 2}

Quadro 2 - Questão 2b: Se não, quais dificuldades são encontradas para tal atitude?

\begin{tabular}{|c|l|}
\hline Professor & Resposta \\
\hline A & $\begin{array}{l}\text { Um dos motivos que não falo a respeito é por ser ACT, ficar pouco } \\
\text { tempo com eles, não me sentindo à vontade de entrar no assunto. }\end{array}$ \\
\hline B & \\
\hline C & \\
\hline D & \\
\hline E & \\
\hline F & \\
\hline G & \\
\hline H & \\
\hline I & \\
\hline J & \\
\hline
\end{tabular}

Fonte: Elaboração dos autores, 2020.

\section{Apêndice B - quadro 3}

Quadro 3 - Questão 4: Em relação aos alunos, como é a reação deles ao tema Sexualidade?

\begin{tabular}{|c|l|}
\hline Professor & Resposta \\
\hline A & $\begin{array}{l}\text { Não conseguem se abrir para conversar a respeito, não se sentem à } \\
\text { vontade com a turma e nem com o professor. }\end{array}$ \\
\hline B & Curiosos de forma geral, porém atentos, alguns tratam com humor. \\
\hline C & $\begin{array}{l}\text { A curiosidade é grande e, automaticamente, as brincadeiras e até } \\
\text { vergonha entram em ação. }\end{array}$ \\
\hline D & Fazem piadinhas, zoam, riam etc. \\
\hline E & $\begin{array}{l}\text { Sexualidade não trabalho, porém, é desenvolvido um trabalho de } \\
\text { gênero. }\end{array}$ \\
\hline F & $\begin{array}{l}\text { Falam com certa tranquilidade, mas, em alguns casos, com discrimi- } \\
\text { nação. }\end{array}$ \\
\hline G & $\begin{array}{l}\text { Não procuro abordar esses assuntos, pois não sei como seria a reação } \\
\text { dos familiares. Esse assunto fica para mediação. }\end{array}$ \\
\hline H & Ficam envergonhados e acabam não socializando. \\
\hline I & Reagem de forma positiva. \\
\hline J & Tema trabalhado com muito cuidado. \\
\hline &
\end{tabular}


Os professores de educação física e as práticas pedagógicas dos temas transversais...

\section{Apêndice C - quadro 4}

Quadro 4 - Questão 5: Em relação aos alunos, como é a reação deles ao tema Drogas?

\begin{tabular}{|c|l|}
\hline Professor & Resposta \\
\hline A & Nunca cheguei a abordar esse tema com eles. \\
\hline B & Tratam de outra realidade, porém, alguns entendem o tema. \\
\hline C & $\begin{array}{l}\text { Agem com cautela, principalmente os alunos que fazem o uso, } \\
\text { demonstram certa preocupação. }\end{array}$ \\
\hline D & Muita zoação e brincadeiras. \\
\hline E & $\begin{array}{l}\text { São abertos a diálogos e reconhecem que faz mal, porém, muitos } \\
\text { acham normal. }\end{array}$ \\
\hline F & $\begin{array}{l}\text { Eles têm uma melhor percepção da situação caótica e como transfor- } \\
\text { ma a vida de uma pessoa. }\end{array}$ \\
\hline G & $\begin{array}{l}\text { Demonstram interesse, pois sempre tem "exemplos". Conhecem os } \\
\text { perigos. }\end{array}$ \\
\hline H & $\begin{array}{l}\text { Socializam com mais facilidade, pois conhecem pessoas e casos a } \\
\text { relatar. }\end{array}$ \\
\hline I & $\begin{array}{l}\text { Há algumas dificuldades, pois tenho alunos que vendem. Devemos } \\
\text { tomar cuidado com a forma de colocar. }\end{array}$ \\
\hline J & Difícil, os adolescentes estão cada vez mais envolvidos com as drogas. \\
\hline
\end{tabular}

Fonte: Elaboração dos autores, 2020

\section{Apêndice D - quadro 5}

\section{Quadro 5 - Questão 6: Em relação aos alunos, como é a reação deles ao tema Violência Doméstica?}

\begin{tabular}{|c|l|}
\hline Professor & Resposta \\
\hline A & Não abordo esse tema com eles. \\
\hline B & Sem o que comentar, não entrei ainda no tema. \\
\hline C & Tema complicado de abordar. Os alunos não demonstram interesse. \\
\hline D & $\begin{array}{l}\text { Surpresa, muitos alunos nem sabem o significado e ficam chocados } \\
\text { com os números. }\end{array}$ \\
\hline E & Pouco comentado e não se abrem pra esse tema. \\
\hline F & $\begin{array}{l}\text { Eles têm a consciência e tentam lutar contra e até mesmo ajudam se } \\
\text { o caso ocorrer. }\end{array}$ \\
\hline G & $\begin{array}{l}\text { Socializam com facilidade e reações positivas quando sabem do cuida- } \\
\text { do que tem que ter com as mulheres. }\end{array}$ \\
\hline H
\end{tabular}


Os professores de educação física e as práticas pedagógicas dos temas transversais...

\begin{tabular}{|l|l|}
\hline I & Normal. \\
\hline J & \\
\hline
\end{tabular}

Fonte: Elaboração dos autores, 2020.

\section{Apêndice E - quadro 6}

\section{Quadro 6 - Questão 7: Em relação aos alunos, como é a reação deles ao tema Qualidade de Vida?}

\begin{tabular}{|c|l|}
\hline Professor & Resposta \\
\hline A & Mostram interesse, me escutam e questionam a respeito. \\
\hline B & $\begin{array}{l}\text { Mostram interesse quando falo sobre as vantagens da boa alimen- } \\
\text { tação e exercício físico. }\end{array}$ \\
\hline C & $\begin{array}{l}\text { Mostram interesse, principalmente o Ensino Médio, pois relacionam o } \\
\text { tema com a aparência visual. }\end{array}$ \\
\hline D & Bem tranquilo, eles sabem dos malefícios e benefícios. \\
\hline E & Bem positivo. \\
\hline F & Estão melhorando a percepção e o entendimento. \\
\hline G & $\begin{array}{l}\text { Eles demonstram conhecimento sobre o tema, porém, poucos colo- } \\
\text { cam em prática. }\end{array}$ \\
\hline H & $\begin{array}{l}\text { Socializam, reagem bem ao tema, mas na prática muitos relatam não } \\
\text { conseguir uma boa alimentação. }\end{array}$ \\
\hline I & Tranquilo. \\
\hline J & Esse tema é melhor de se trabalhar. \\
\hline
\end{tabular}

Fonte: Elaboração dos autores, 2020.

\section{Apêndice F - quadro 7}

Quadro 7 - Questão 8: Em relação aos alunos, como é a reação deles ao tema Preconceito?

\begin{tabular}{|c|l|}
\hline Professor & Resposta \\
\hline A & Não abordei esse tema com eles. \\
\hline B & Eles não toleram de forma geral. \\
\hline C & $\begin{array}{l}\text { A maioria se nega a aceitar que pratica, já está alocado na sociedade, } \\
\text { por isso, tema difícil de trabalhar. }\end{array}$ \\
\hline D & $\begin{array}{l}\text { Existe uma resistência, pois, às vezes, eles são preconceituosos e não } \\
\text { gostam de falar sobre e também existe falta de conhecimento sobre o } \\
\text { que é preconceito. }\end{array}$ \\
\hline
\end{tabular}


Os professores de educação física e as práticas pedagógicas dos temas transversais... Philipe Guedes Matos • Carina Cechinel da Silva

\begin{tabular}{|c|l|}
\hline E & Na teoria todos sabem, mas na prática é bem difícil. \\
\hline $\mathrm{F}$ & $\begin{array}{l}\text { Existe bastante dificuldade, em relação a raça, cor, sexualidade, mas } \\
\text { estão ficando mais conscientes. }\end{array}$ \\
\hline $\mathrm{G}$ & Observo preconceito em relação à classe social. \\
\hline $\mathrm{H}$ & $\begin{array}{l}\text { Se comovem com a turma e procuram tratar as pessoas com respeito, } \\
\text { em determinados casos, eles mesmos intervêm nas situações adver- } \\
\text { sas. }\end{array}$ \\
\hline $\mathrm{I}$ & Tranquilo. \\
\hline $\mathrm{J}$ & Muito difícil, muitos adolescentes não têm respeito ao próximo. \\
\hline
\end{tabular}

Fonte: Elaboração dos autores, 2020.

\section{Apêndice G - quadro 8}

Quadro 8 - Questão 9: Além dos temas transversais citados nessa pesquisa, tem algum outro em que você aborda em sala de aula? Se sim, qual?

\begin{tabular}{|c|l|}
\hline Professor & Resposta \\
\hline A & Não, costumo passar mais conteúdos sobre os esportes. \\
\hline B & $\begin{array}{l}\text { Sim, temas como profissão, futuro e relacionamentos em seu entor- } \\
\text { no. }\end{array}$ \\
\hline C & Sim, o bullying e o respeito às individualidades. \\
\hline D & Sim, gêneros. \\
\hline E & Sim, gênero, liderança e suas implicações no mercado de trabalho. \\
\hline F & \\
\hline G & Não. \\
\hline H & Sim, trabalho em equipe, responsabilidade e combate à violência. \\
\hline I & Sim, respeito e amizade. \\
\hline J & \\
\hline
\end{tabular}

Fonte: Elaboração dos autores, 2020.

\section{Publisher}

Universidade Federal de Goiás. Faculdade de Educação Física e Dança. Publicação no Portal de Periódicos UFG. As ideias expressadas neste artigo são de responsabilidade de seus autores, não representando, necessariamente, a opinião dos editores ou da universidade. 